\title{
Embodied GHG emissions of building materials in Shanghai
}

\author{
Beijia Huanga,b*, Yanxi Chen ${ }^{\mathrm{a}}$, Will McDowall ${ }^{\mathrm{c}}$, Serdar Türkeli ${ }^{\mathrm{d}}$, Raimund Bleischwitz ${ }^{\mathrm{c}}$, Yong \\ Geng $^{\mathrm{e}}$ \\ ${ }^{a}$ College of Environment and Architecture, University of Shanghai for Science and Technology, \\ Shanghai, China \\ ${ }^{\mathrm{b}}$ Center for Industrial Ecology, School of Forestry and Environmental Studies, Yale University, \\ New Haven, CT, USA \\ c Institute for Sustainable Resources, University College London, London, United Kingdom \\ ${ }^{d}$ United Nations University-MERIT/Maastricht University, Maastricht, the Netherland \\ ${ }^{\mathrm{e}}$ China Institute for Urban Governance, Shanghai Jiao Tong University, Shanghai, China
}

\begin{abstract}
Globally, construction materials are the largest materials flow entering urban areas after water. The tremendous use of building materials poses heavy threats to resources and the environment. In order to better understand the GHG emissions embodied in the abundant building material consumption of Shanghai's buildings and search for approaches to reduce GHG emissions, this study explores the building consumption and the embodied GHG emission in Shanghai's buildings through life cycle assessment. Novel and localized life cycle inventories are applied. Based on our findings, the average annual growth rate of new constructed area in Shanghai was around $10 \%$ since 2000 to 2016 . Concrete, brick, sand, gravel and cement (non-concrete use) appear as the main materials used. High GHG emission burden materials per $\mathrm{kg}$ are revealed to be steel, lime, wood, glass and cement (non-concrete use). Accounting the annual material consumption in 2016, steel, cement (non-concrete use), concrete and brick are found have the highest contribution to embodied GHG emission in Shanghai. The decoupling analysis reveals Shanghai experienced a general trend from non-decoupling to relative decoupling between building material use and GDP in recent 17 years. Findings in this study indicate for the high GHG emission burden materials such as steel and lime, reducing the energy use and using less $\mathrm{CO}_{2}$-intensive energy sources during manufacturing are likely to be the most effective approaches. In terms of the highly consumed building materials such as concrete and brick, the focus should be on reducing consumption or looking for substitute materials with lower GHG burden per unit.
\end{abstract}


Key words: building materials; GHG; life cycle assessment; Shanghai, decoupling analysis

\section{Introduction}

The construction industry is a key industry of global social and economic development, and it is also a large consumer of resources. Buildings account for more than $40 \%$ of global energy use and account for around 18\% of global GHG emissions (Intergovernmental panel on climate change, 2014). The building materials used in the construction industry are transformed from materials extracted from the earth's crust. The extensive use of building materials has a major impact on resource consumption and the environment, and greenhouse gas (GHG) emissions is one of important environmental impacts. Previous studies mainly focus on energy consumption and GHG emissions in the operation process since this period is deemed to be a major contribution of the building's life cycle GHG emissions. However, with recent advances in reducing the operation carbon of buildings, there is a clear shift in attention towards investigating strategies to minimize embodied carbon emissions (Dimoudi and Tompa, 2008; Akbarnezhad and Xiao, 2017).

There are many studies investigating building material consumption in the urban scale. Tanikawa and Hashimoto (2009) applied the 4D-GIS method to analyze the temporal and spatial dynamic changes in buildings and transport facilities in Manchester, England, Wakayama and Japan. There are also researches focused on building material flows and stocks at the urban scale in China. Huang et al. (2015), Li et al. (2016), Hong et al. (2016) used Material Flow Analysis (MFA) models to calculate material stock of urban infrastructure materials, and predict building material stock in China from 2010 to 2050. As for embodied GHG emissions of buildings, Alonso et al. (2011) and Wiik et al. (2018) assessed GHG emissions produced by building envelope materials and found some potential ways to minimize emissions such as facade design strategies. Different methodologies are applied to the assessment of greenhouse gas emissions in the construction industry. Nägeli et al. (2018) developed a new method of building stock modeling and GHG emissions accounting based on the generation of 
synthetic building stocks. Chen et al. (2015) examined the limitation of the existing building environmental assessment tools and established an embodied GHG emissions assessment integrated tool (including product category, GHG auditing, and benchmarking) for identifying real low carbon building materials. Generally, carbon inventories are used as the basis for the cradle to gate embodied carbon emissions analysis (Hammond and Jones, 2006; Hong et al., 2014). Yan et al. (2010) indicated that embodied GHG emissions of concrete and steel account for $94 \sim 95 \%$ among the total building materials, and thus the use of recycled building materials especially steel can decrease the GHG emissions in a considerable amount. Some researchers (Begum and Pereira, 2010; Rasmussen et al., 2018) analyzed the approaches to reduce GHG emissions claimed that increasing the energy efficiency of producing building materials can effectively reduce GHG emissions.

A fair number of researches further explore the relationship between GHG emission and economic development, while mostly focus on the industrial scope instead of the building sector. Among the various observing approaches, decoupling analysis appear as a key methodology (OECE, 2002; Tapio et al., 2005; Wang and Yang, 2015; Wang et al., 2017). Vavrek and Chovancova (2016) studied the relationship between economic development and greenhouse gas emissions in the V4 countries (Czech Republic, Slovakia, Hungary and Poland) in the period of 1991-2012 based on decoupling model theory, and detected strong decoupling phenomenon. Zhao et al. (2016) revealed a weak decoupling of China's carbon dioxide emissions and industrial growth since 1993 to 2013 .

As a typical municipality in China, the rapid development of Shanghai's urban construction and the coordinated development of resources and environment have become an important issue in the process of urbanization. According to the Shanghai Statistical Yearbook (SMSB, 2017), in 2016 the gross output value of the construction industry reached more than 600 billion $\mathrm{RMB}$, and the annual construction area of the construction industry increased from 19 million $\mathrm{m}^{2}$ in 2000 to more than 74 million $\mathrm{m}^{2}$ in 2016. Our literature review finds that there are no studies that have evaluated the GHG emissions of buildings in Shanghai based on spatial and temporal data. In order 
to better understand the GHG emissions embodied in the substantial building material consumption of Shanghai's buildings and search for approaches to reduce GHG emissions, our study aims to evaluate the embodied GHG emissions of building materials in Shanghai from 2000 to 2016. In the first step, annual constructed residential and non-residential buildings will be counted; Secondly, building material consumption will be calculated based on the building material intensity and annual construction area; Thirdly, GHG emissions will be quantified using life cycle assessment based on the production inventory for each material and corresponding material consumption amount; Finally, decoupling analysis is conducted in order to reveal the corresponding relation between building material consumption and local GDP growth .

\section{Methodology}

\subsection{Research boundary}

The embodied GHG emissions in this study indicate the greenhouse gas emissions associated with production of construction materials, mainly including the material exaction and production process (cradle to gate), but excluding material transportation, construction, as well as the operation and demolition of buildings. The input and output inventory data of building materials production in this study is from the Sinocenter database $^{1}$ of the Beijing University of Technology and Gabi database, which is the most comprehensive building material database in China. Among the 10 materials analyzed in our study, most material inventories are from the Sinocenter database, only the inventory of steel and cement is from Chinese database in Gabi, as Sinocenter has not covered these two materials.

According Shanghai statistical yearbooks (SMSB, 2001-2017), buildings are divided into residential buildings and non-residential buildings. In which the nonresidential buildings refer to plant, education, warehouse, office, commercial, hospital,

\footnotetext{
${ }^{1}$ This sino-center database is original from research group in Beijing University of Technology, which is the most comprehensive database of building materials in China. If you have any question, please contact Prof. Gong, Email: gongxianzheng@bjut.edu.cn, address: College of Materials Science and Engineering, Beijing University of Technology, 100 Pingleyuan, Chaoyang District, Beijing, China
} 
hotel, and other buildings. The key building material categories are divided into steel, concrete, cement (non-concrete use), wood, brick, sand, gravel, limestone, glass, and ceramic tiles (Chang, 2016).

\subsection{Research process and methodology}

The research framework of this study is shown in Fig.1.

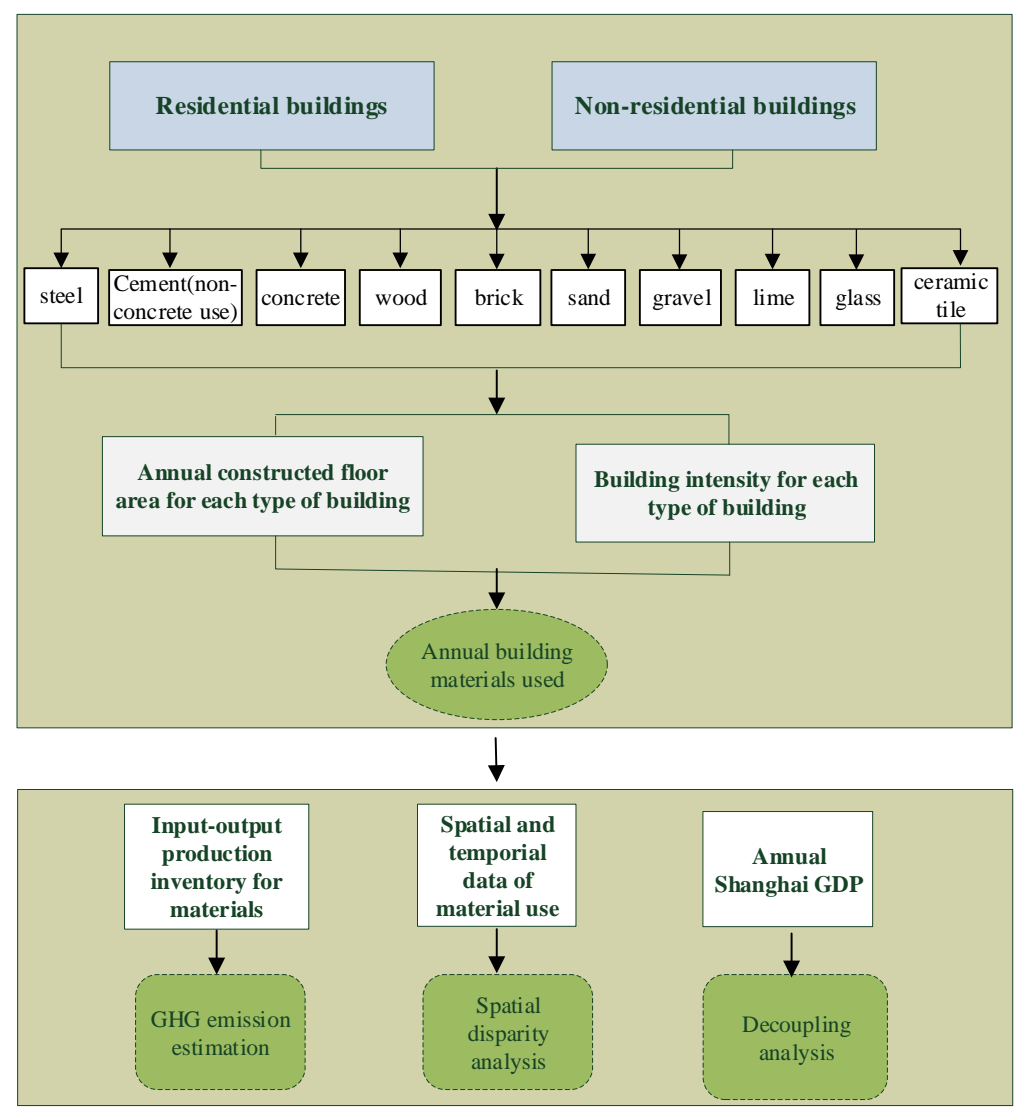

Fig. 1. Research framework

\subsubsection{Building materials consumption}

The annual material use can be calculated by the building materials use intensities (MI) and the annual newly constructed building area (Formula 1):

$$
\mathrm{MU}_{\mathrm{i}, \mathrm{j}}^{\mathrm{t}}=\sum_{\mathrm{j}=1}^{2}\left(\mathrm{~S}_{\mathrm{i}, \mathrm{j}}^{\mathrm{t}} \cdot \mathrm{MI}_{\mathrm{i}, \mathrm{j}}^{\mathrm{t}}\right)
$$

where MU is the materials of type $\mathrm{i}$ added to the flow of buildings in $\mathrm{kg}$ in year $\mathrm{t}$, summed for the two building types $\mathrm{j}$; $\mathrm{S}$ is the newly constructed building area in year $\mathrm{t}$; MI is the mass of building material $(\mathrm{kg})$ per unit of constructed area $\left(\mathrm{m}^{2}\right)$, namely the building material use intensity $(\mathrm{MI})\left(\mathrm{kg} / \mathrm{m}^{2}\right)$. 
The data of annual constructed building area (S) of residential and non-residential buildings are derived from Shanghai Statistical Yearbook (SMSB, 2001-2017) and Construction Industry Statistical Yearbook (NSBF, 2001-2017).

The consumption of building materials varies according to the construction area, building structure, building height, architectural modeling, and construction technology. Due to the wide range of construction characteristics, MI in this study is based on statistical reports and data from the literature. The primary referred data sources are standards of the consumption of major materials for construction projects (Building Construction Manual, 2003; Zhao et al., 2014), Statistical Yearbook (National Bureau of Statistics of the People's Republic of China. 2001-2017) and published literatures (Chang, 2016; Han and Xiang, 2013; Huang et al., 2013; Huang et al., 2017). The MI for residential buildings and non-residential buildings are shown in Fig.2.

(a)

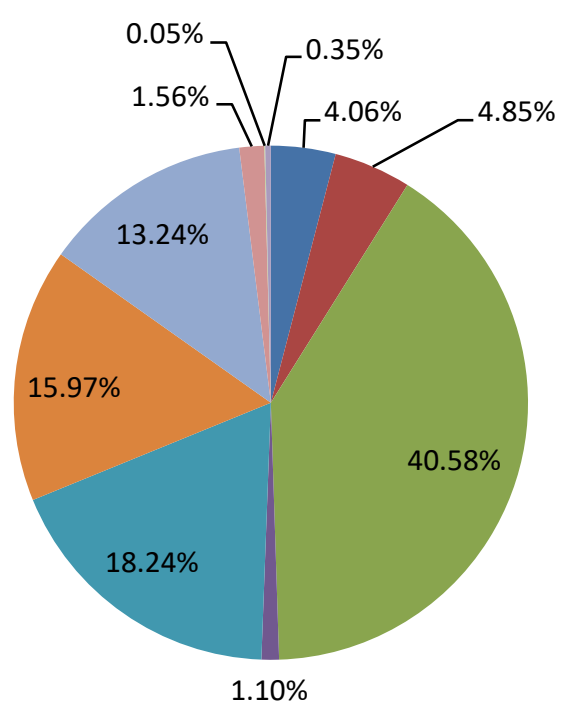

(b)

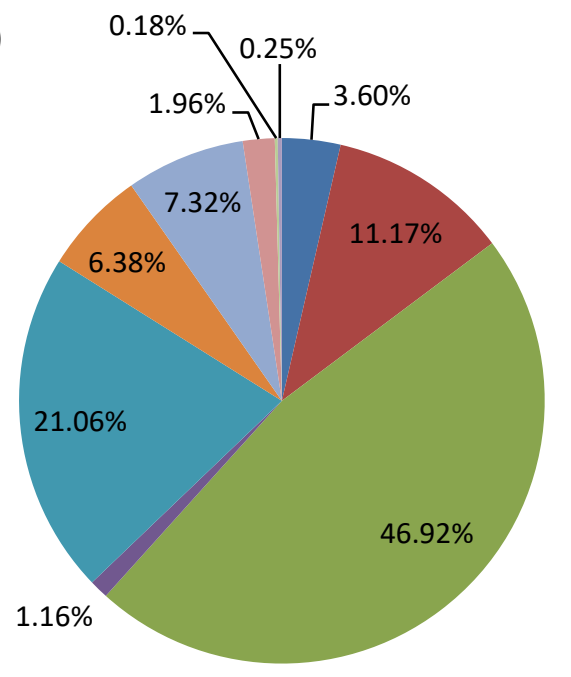

steel

cement (nonconcrete use) concrete

wood

brick

sand

gravel

n lime

glass

nceramic tile

Fig.2. Building material intensity in Shanghai (2014)

(a) Residential buildings (b) Non-residential buildings

As shown in Fig.2, the highest consumption proportion materials are found to be concrete and brick in both the residential buildings and the non-residential buildings. Concrete accounts for nearly $50 \%$ of the total building material consumption. Meanwhile, there are also some proportional differences--the non-residential buildings have higher proportion of concrete and cement (non-concrete use), and lower 
proportion of sand and gravel instead. According to our interview with construction engineers, non-residential buildings usually require more concrete to support heavier loads.

\subsubsection{Embodied GHG emissions}

The environmental impact per kilogram of building material (Ek) is assessed by applying the mid-point parameters of the ReCiPe 2016 method. Life Cycle Assessment (LCA) method ReCipe (Goedkoop et al., 2009; Schryver et al., 2009) is used as it is currently one of the most widely used LCA methods. Life cycle impact assessment (LCIA) translates emissions into a limited number of environmental impact scores by means of so-called characterization factors (Hauschild and Huijbregts, 2015). There are usually two ways to derive the characterization factor, ie at the midpoint level and the endpoint level. This study uses the method of ReCipe in Gabi software to quantitatively assess the climate change caused by the consumption of building materials for various types of buildings.

Where $\mathrm{Ek}$ is the GHG emissions of per $\mathrm{kg}$ of building material. In addition to assessing GHG emissions of per kg of building material (Ek), we also consider annual material use (Ev) to evaluate GHG emissions. This is important because the amount of material used for a particular building is different, and it is likely that the material with a higher environmental load will have a lower consumption rate. Ev is calculated according to Formula 2.

$$
\mathrm{Ev}_{\mathrm{i}}^{\mathrm{t}}=\sum_{\mathrm{j}=1}^{2}\left(\mathrm{Ek}_{\mathrm{i}, \mathrm{j}}^{\mathrm{t}} \cdot \mathrm{MU}_{\mathrm{i}, \mathrm{j}}^{\mathrm{t}}\right)
$$

Where Ev is the total embodied GHG emissions for material i in year $t$, summed for the two building types $\mathrm{j}$; Ek is embodied GHG emissions per $\mathrm{kg}$ building material for material i; MU is the materials of type i added to the stock of buildings.

\subsubsection{Decoupling analysis}

Researchers have developed various decoupling indicators to track the temporal changes in the relationship between resource pressures and economic growth (Sjöström 
and Östblom, 2010; Yu et al., 2017). The decoupling Index (DI) proposed by Tapio (2005) is widely used in much existing research (Diakoulaki and Mandaraka, 2007; Vehmas et al., 2007; Li et al., 2015) for analyzing the relationship between economic growth and energy consumption. Decoupling of embodied GHG emissions growth from economic growth can be expressed by Formula 3:

$$
\mathrm{DI}=\frac{\Delta \mathrm{GHG} \%}{\Delta \mathrm{GDP} \%}
$$

Where DI is the decoupling index; $\triangle \mathrm{GDP} \%$ is the annual change rate of GDP; $\Delta \mathrm{GHG} \%$ is the annual change rate in the embodied GHG emissions. The decoupling correlation is classified based on the value of DI, eight logical possibilities can be distinguished (Yu et al., 2017). Shanghai population and GDP refer to the Shanghai Statistical Yearbook (SMSB, 2001-2017).

Eight logical possibilities are shown in Fig. 3.

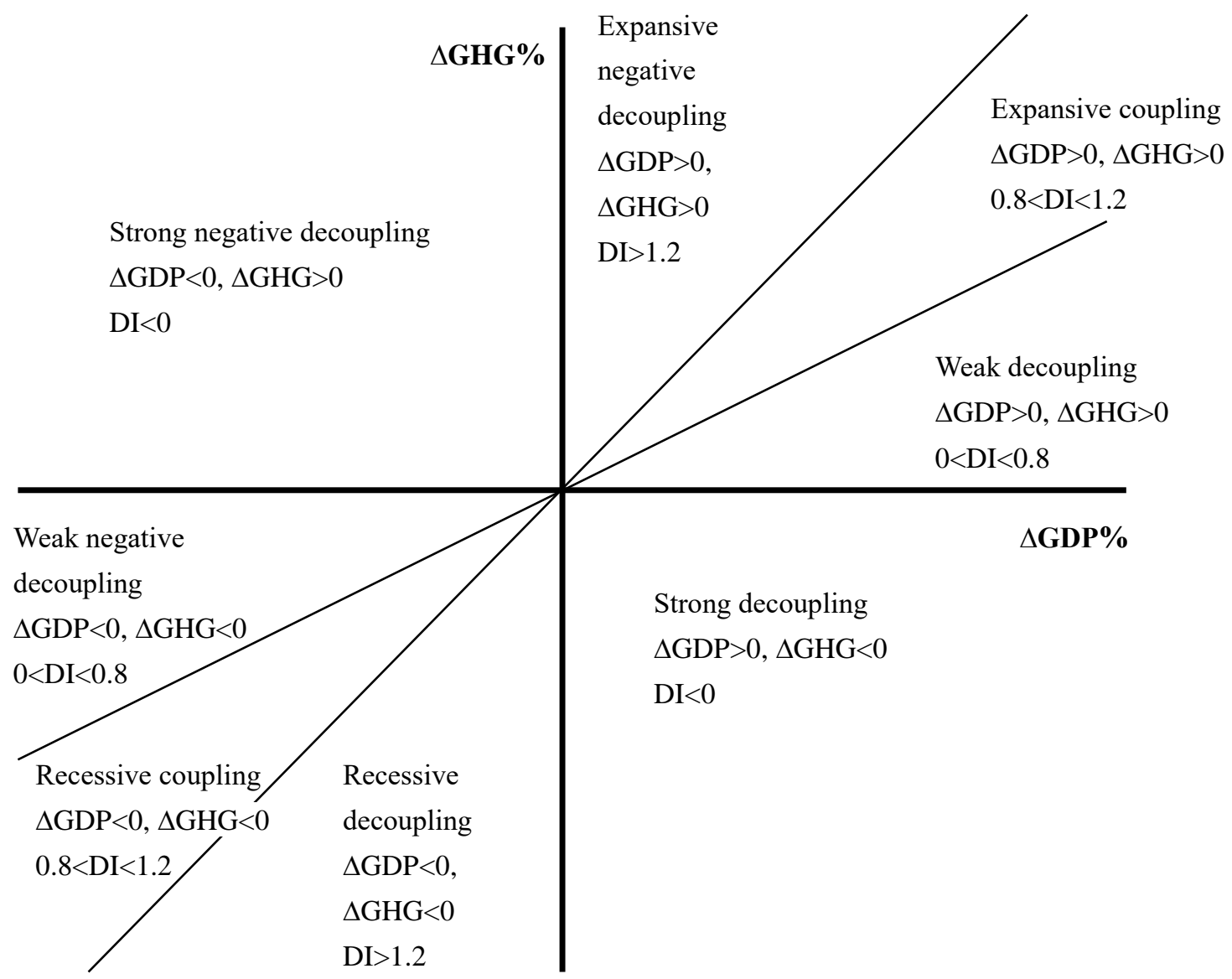


Fig. 3. The degree of coupling and decoupling of GHG emissions reduction from economic growth. The two lines represent that DI $=0.8$ or 1.2 and the states are both coupling (modified from Tapio, 2005).

\section{Results}

\subsection{Building materials use}

\subsubsection{Annual constructed building area in Shanghai (2000-2016)}

The construction area of Shanghai's buildings experienced volatile growth from 2000 to 2016, and the average annual growth rate of the newly constructed building areas reached $10.7 \%$ in this period. Both residential and non-residential buildings grew rapidly between 2000 and 2006. From 2007, the residential buildings began to decrease, probably because of the land use control of Shanghai government (Shanghai Municipal Planning and Land Resources, 2006-2020). In 2008, the construction area of nonresidential buildings dropped substantially, perhaps due to the economic impacts of the global financial crisis (China Report Hall,2009). After 2009, annual constructed building areas of residential building and non-residential buildings both present a gradually increasing trend. Since 2015, constructed residential building in Shanghai began to decline again. This phenomenon is in correspondence to the strict land exploitation control activity in Shanghai (Diakoulaki and Mandaraka, 2007). In the government report of "City development plan from 2017 to 2035" (Shanghai Urban Master Plan, 2018), Shanghai has set its plan to control land use within 32 million $\mathrm{m}^{2}$. The plan also pointed out that instead of continuing to construct new buildings, attentions should be paid to enhancing the function of existing buildings. 


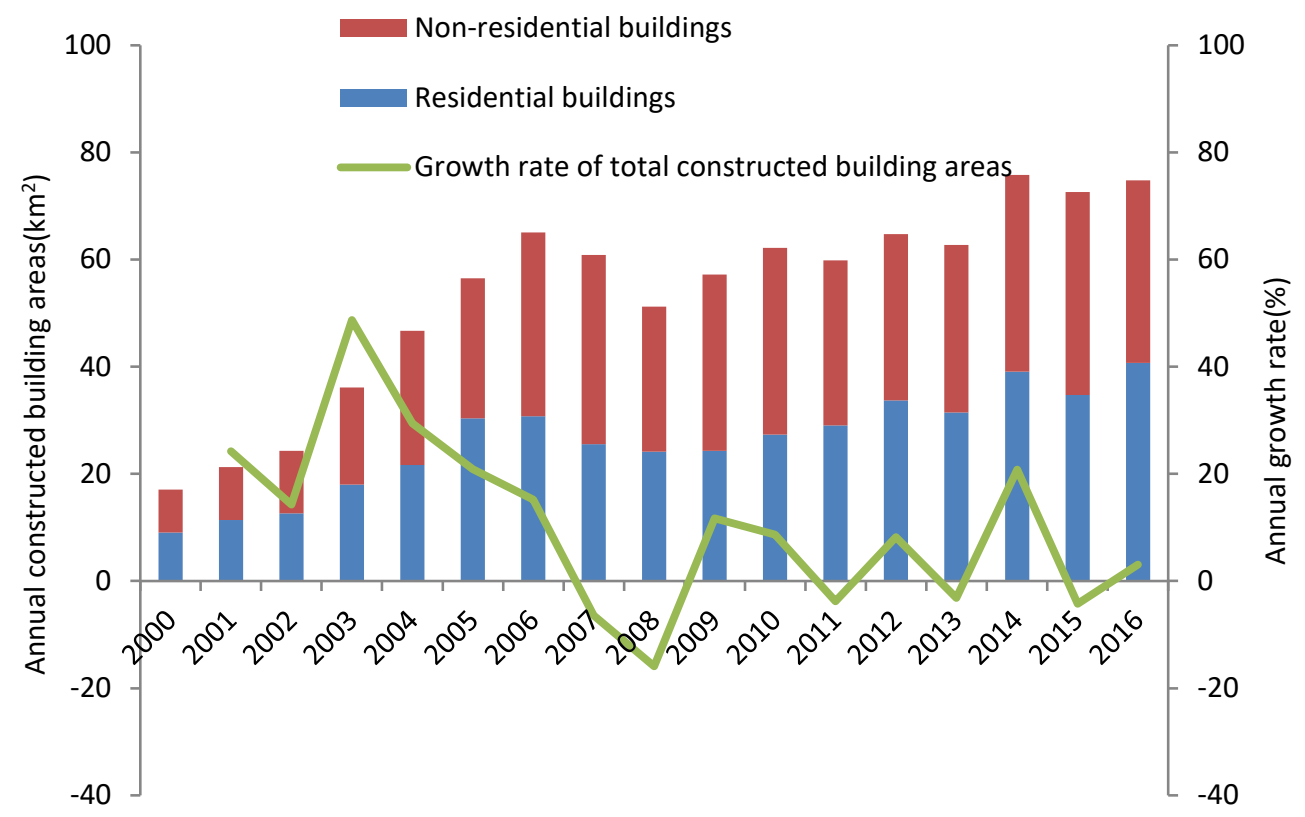

Fig.4. Annual constructed building areas in shanghai (2000-2016)

\subsubsection{Annual building materials use (2000-2016)}

Material consumption arising from construction of residential buildings in Shanghai more than tripled from $18.57 \mathrm{Mt}$ in 2000 to $83.58 \mathrm{Mt}$ in 2016 . Material consumption arising from the construction of non-residential building grew less than that from residential buildings, rising from $15.19 \mathrm{Mt}$ in 2000 to $64.33 \mathrm{Mt}$ in 2016 . After 2010, Shanghai's inflow growth rates became relatively static. Several other researchers also indicated that the annual demand for building materials in China began to decrease around 2010 (Hong et al. 2016), and make a further prediction that building material accumulation will reach its peak in 2030 (He et al.2013). Among the building materials, concrete appear as the largest demand for building materials, followed by brick, sand, and cement (non-concrete use). The demand for steel, wood, and ceramic tile is relatively low (see in Fig. 5 and Fig.6). Data of annual building area is available in our supporting information in Table S1 and Table S2. 


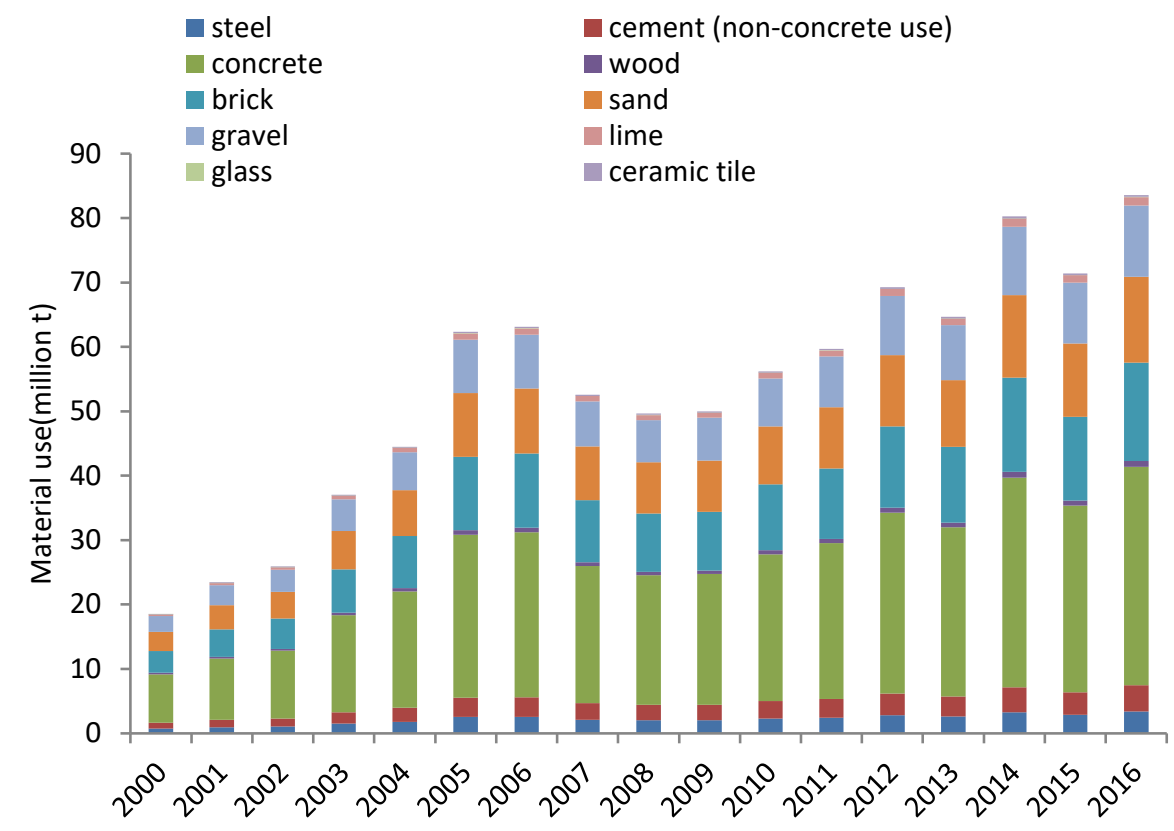

Fig.5. Annual use of building materials for residential buildings (2000-2016)

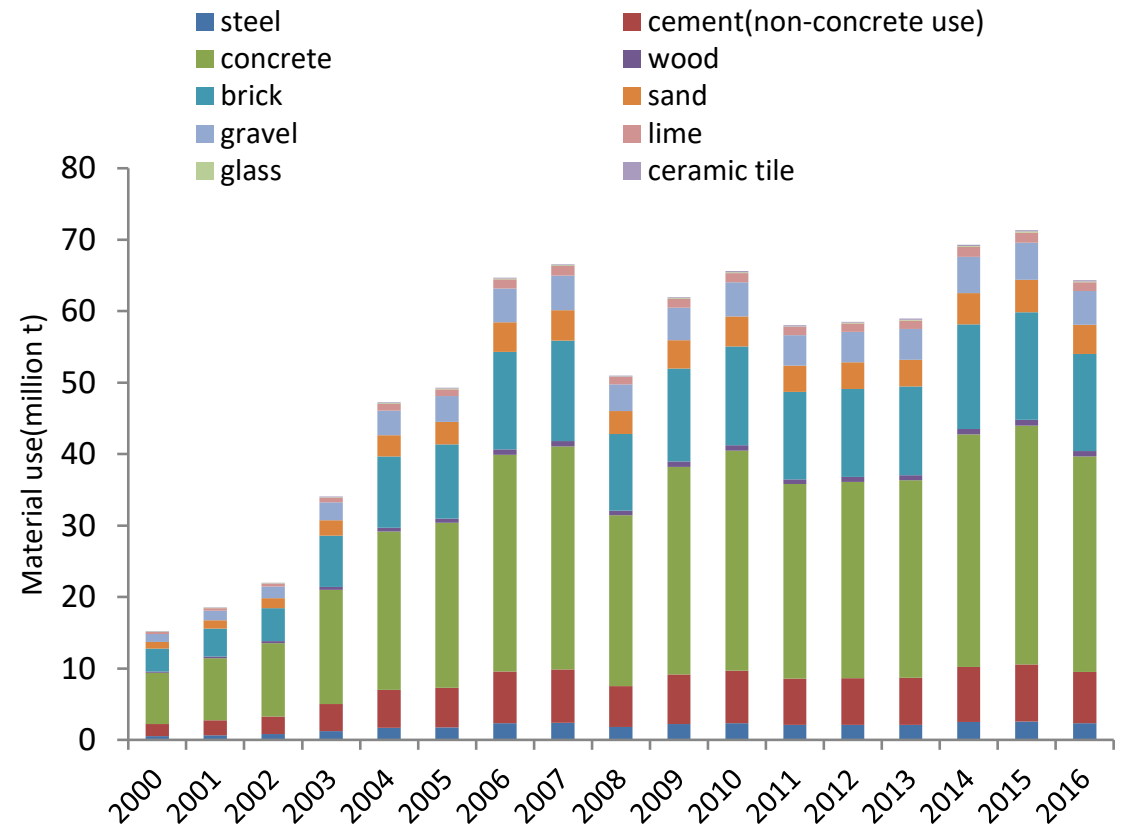

Fig.6. Annual use of building materials for non-residential buildings (2000-2016) 


\subsection{Embodied GHG emissions in Shanghai's buildings}

\subsubsection{Embodied GHG emissions per kg building material}

GHG emissions per kilogram of material were quantified using the normalized ReCiPe midpoint impact (Fig. 7). The GHG emissions caused by the production of steel, lime, wood, and glass per kg is quite large. In contrast, sand, concrete and brick have relatively lower per mass environmental impacts contribution.

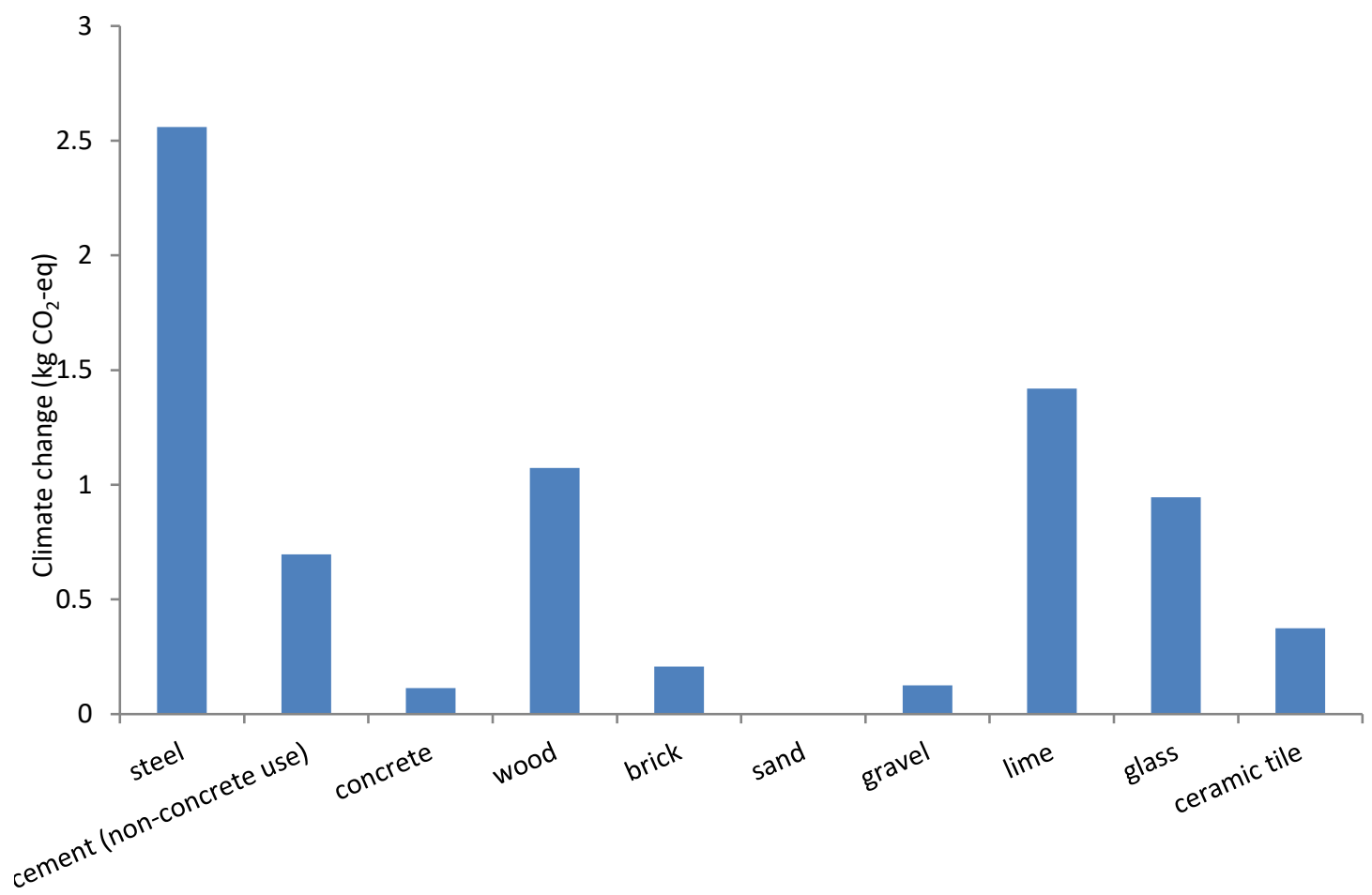

Fig.7. Associated embodied GHG emissions per kg building material $\square 2015 \square$

\subsubsection{Embodied GHG emissions in Shanghai's buildings in 2000-2016}

Change of embodied GHG emissions from residential buildings and nonresidential building materials in Shanghai in our research period has similar trend as the annual material consumption. Thus, we choose 2016 to show the proportion of GHG contribution from different building types and materials (Fig.8). The production of steel, cement (non-concrete use), concrete and brick accounts for a large amount of GHG emissions. Based on previous analysis (see in Fig.2, Fig.5, Fig. 6 and Fig.7), the contribution of GHG emissions from steel is mainly due to the high environmental 
burden per $\mathrm{kg}$ unit, while the contribution of GHG emissions from cement (nonconcrete use), concrete and brick are mainly because of the high annual consumption amount. In general, steel and cement (non-concrete use) are the most important sources of GHG emissions. For the steel production in China, the most promising approach to reduce GHG emissions is to increase the recycling rate of scrap steel in the Basic Oxygen Furnace (BOF) (Sheinbaum et al.2010; Yu et al.2015; Kuramochi, 2016). As for the cement (non-concrete use) production, Wang et al. (2013) identified that energy consumption in the cement (non-concrete use) production and chemical reaction in the clinker process are the dominant sources of GHG emissions. The International Energy Agency (IEA) suggests several ways to reduce GHG emissions in cement (non-concrete use) production (IEA,2009), including enhancing energy efficiency, applying alternative fuels, seeking for clinker substitution, and using carbon capture and storage (CCS). Among these approaches, enhancing the energy efficiency is claimed to be the most promising way in the near term (Valderrama et al., 2012; Benhelal et al., 2013; Galvez-Martos and Schoenberger, 2014).

(a)

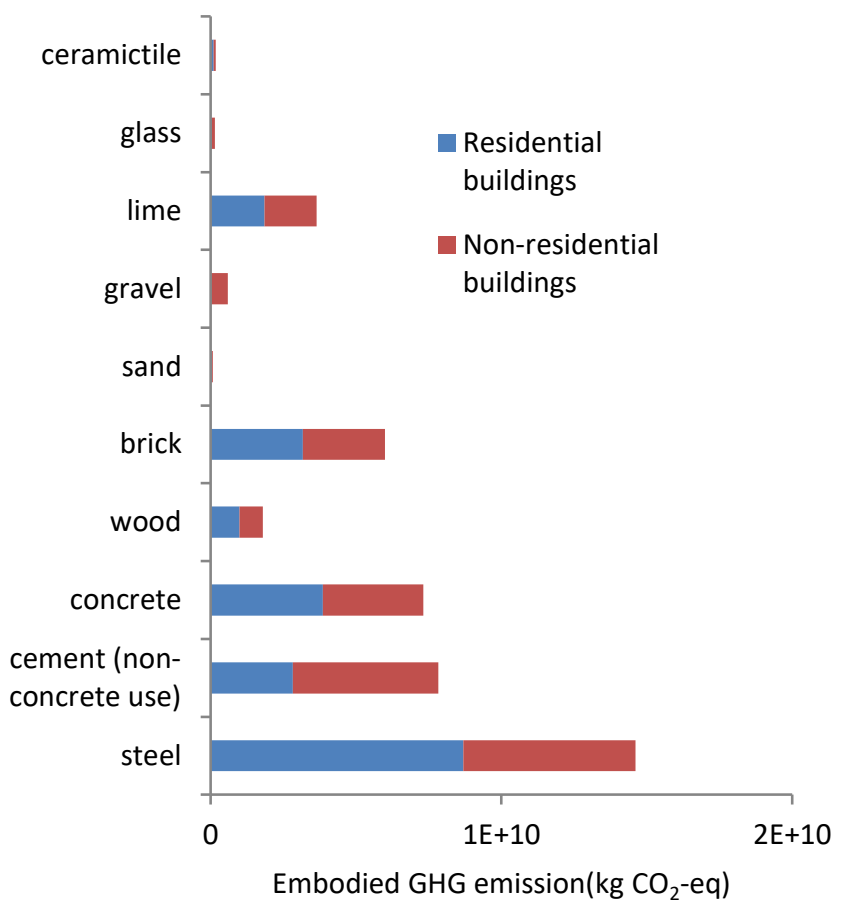

(b)

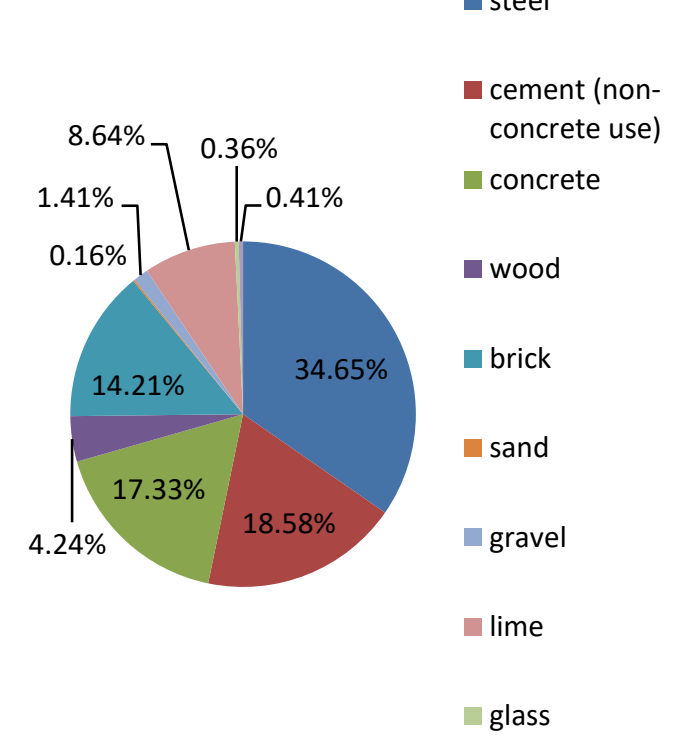

Fig. 8. Embodied GHG emissions in residential buildings and non-residential buildings (a); GHG contribution proportion of different building materials (b) (2016) 


\subsection{Spatial disparity}

In order to further study the spatial pattern of Shanghai's embodied GHG emissions, we conducted a study on embodied GHG emissions in Shanghai's various districts. 2003, 2008 and 2016 are selected as the investigated year. 2003 is selected as a case study year instead of 2000 since the statistical data between 2000 to 2002 had not covered each district in Shanghai. 2008 is selected because the economic crisis in 2008 detected had a great impact on the building material consumption. And 2016 is the most current year in our studied period. The annual new building area and embodied GHG emissions can be found in our supporting information Table S3, Table S4 and Table S5. 
(a)

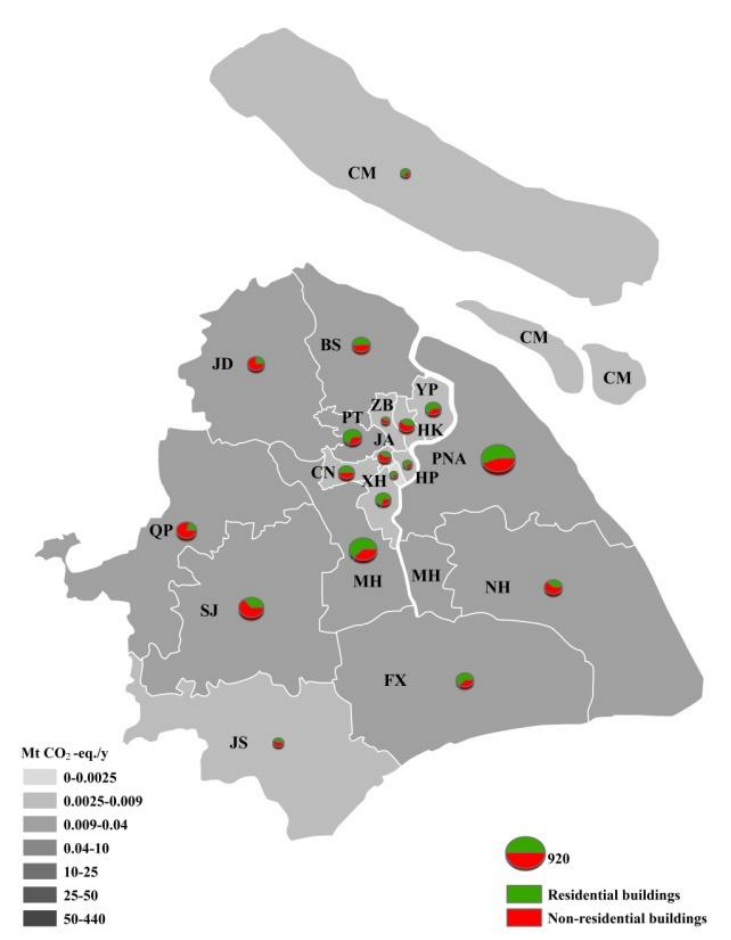

(b)

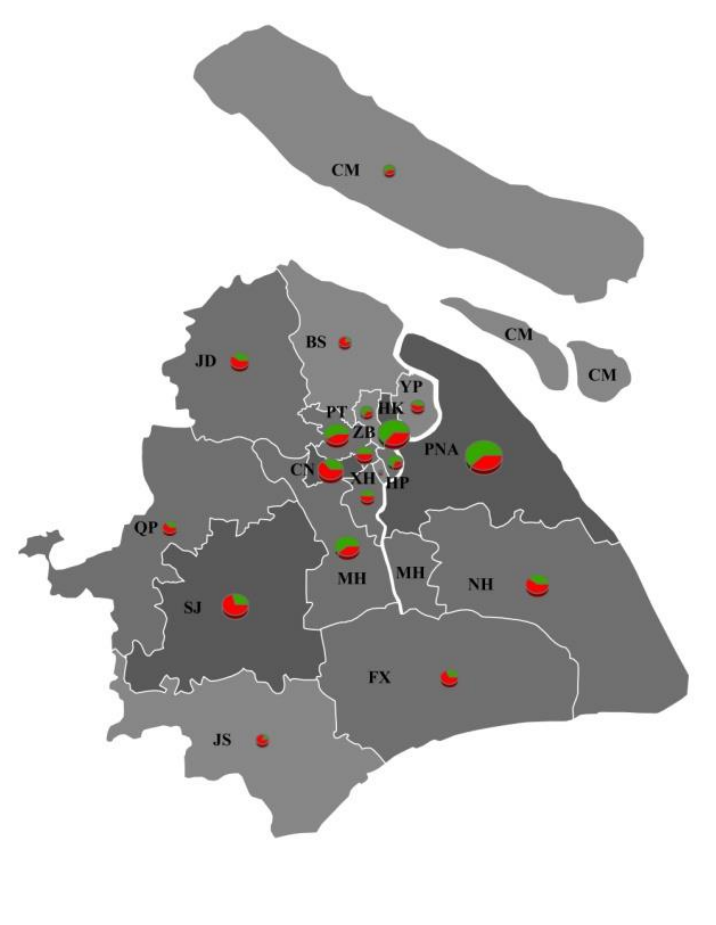

(C)

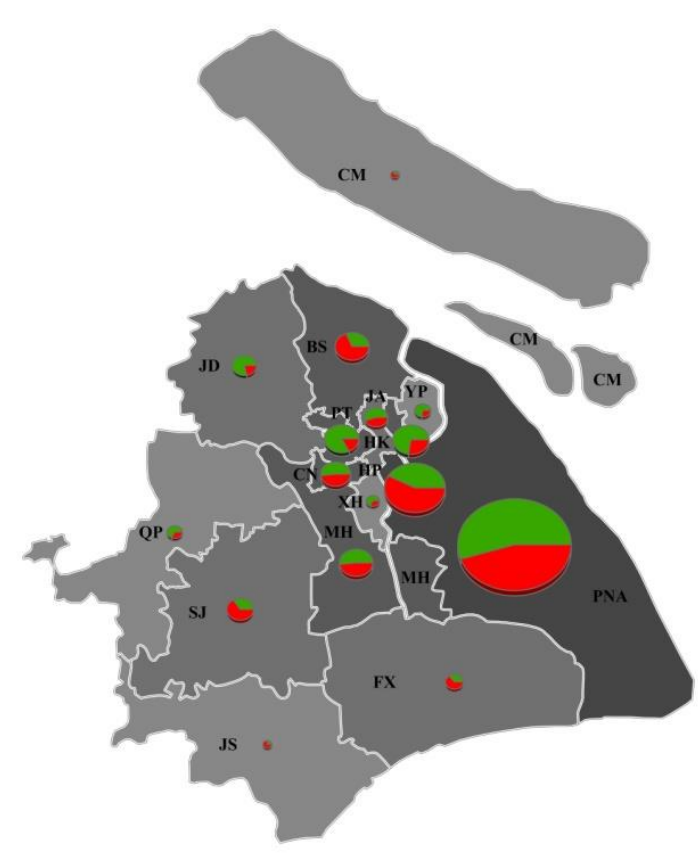

Fig.9. Spatial distribution of building area and embodied GHG emissions in Shanghai in 2003(a), 2008(b) and 2016(c)

Note: 1. The size of circles in Fig.9 represents the annual new building area of residential and non-residential buildings in various districts of Shanghai $\left(10,000 \mathrm{~m}^{2}\right)$; the darkness of each district indicates the amount of $\mathrm{GHG}$ emissions $\left(\mathrm{Mt} \mathrm{CO}_{2}\right.$-eq). 2. Full name and short name for the districts in Shanghai: $\mathrm{CM}(\mathrm{Chongming})$; PNA (Pudong New Area); JS(Jinshan); QP(Qingpu); JD: (Jiading); BS(Baoshan); FX (Fengxian); MH(Minhang); XH(Xuhui); HP(Huangpu); ZB(Zhabei); CN(Changning); PT(Putuo); HK(Hongkou); YP(Yangpu); JA(Jingan); LW(Luowan); NH(Nanhui); SJ (Songjiang). 3. NH is merged into PNA in 2010. 
As seen in Fig.9, construction activities in 2003 mainly remained in PNA, MH, and SJ. In 2008, active construction became much slower and mainly focused on the central districts. In more recent years, building construction mainly took place in the eastern PNA district and also the city center HP district. The southern JS, QP district, and the $\mathrm{CM}$ island district kept slower construction activities than other districts in the whole period. Possible reasons for this may be $\mathrm{CM}$ aims to remain as a natural ecological island with restriction for high industrial development (Shanghai Chongming District Development and Reform Commission, 2018). In terms of QP and JS, both of the them have stable GDP income contributed by the district located hi-tech industrial parks for a long term, resulting less active building construction (Shanghai Qingpu District Economic Committee, 2018; Shanghai Jinshan District Government Documents, 2018).

In general, the building construction in Shanghai within the recent 17 years gradually moved from the central Shanghai to northern and then the eastern part. Embodied GHG emissions shows the similar trend.

\subsection{Decoupling analysis}

According to Shanghai Statistical Yearbook (2001-2017), Shanghai's GDP kept increasing in this period $(\Delta \mathrm{GDP} \%>0)$. As indicated in Fig.10, the decoupling index of building material consumption and GDP varied greatly since 2000 to 2016 (In order to smooth short-term fluctuations, two-year moving average values are plotted in the figure). Decoupling index of building material embodied GHG emissions and GDP appeared expansive negative decoupling (DI >1.2) before 2006. During the period from 2007 to 2015, the decoupling index fluctuated between expansive coupling and weak decoupling in most of the time. Strong decoupling happened in 2008 and 2016, because the material consumption had obvious decline in the two years. The decline in 2008 may have been caused by the economic crisis, while whether the decoupling in 2016 indicates the GDP in Shanghai enter into a period of lower reliance on building construction still remains to be seen. 


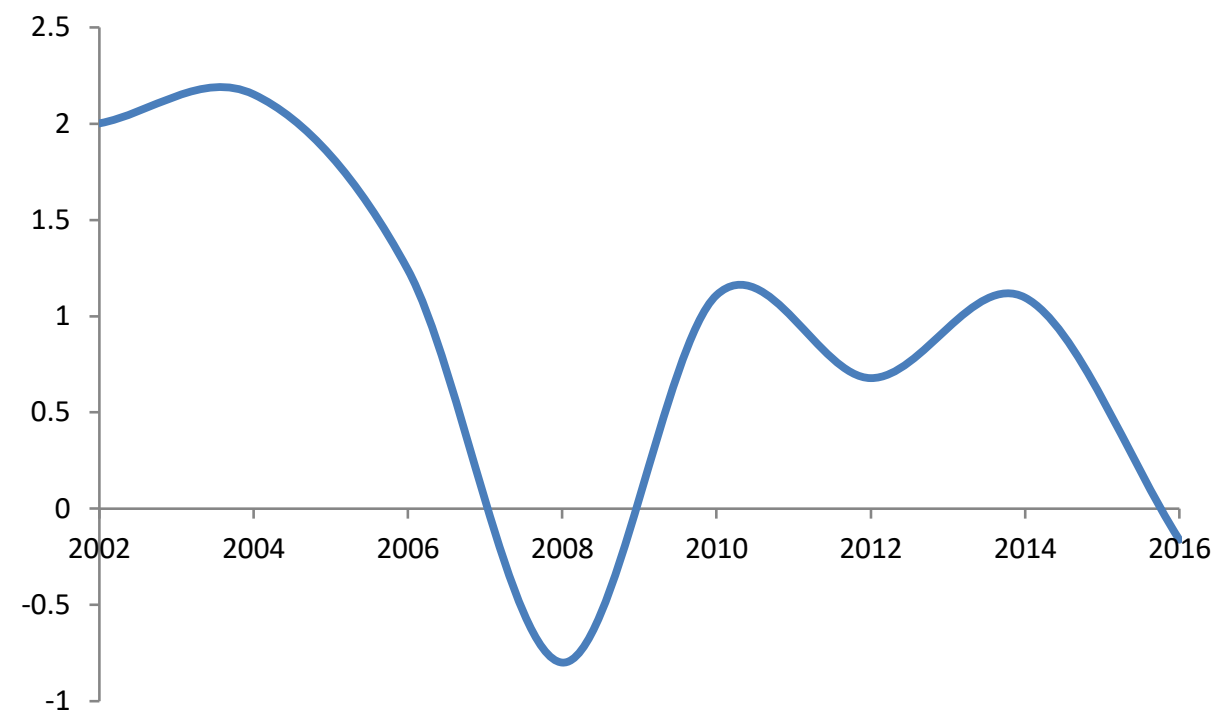

Fig.10. Decoupling index of embodied GHG emissions and GDP (2000-2016) (Two-year moving average values are plotted in the figure) 


\section{Conclusion and discussion}

The average annual growth rate of new constructed areas in Shanghai was around $10 \%$ from 2000 to 2016 . After 2010, Shanghai's growth rate became relatively static. Among the building materials, concrete appear as the largest demand by mass for building materials, followed by brick, sand, gravel and cement (non-concrete use). The demand for steel, wood, and ceramic tile is relatively low. The building material composition is quite different with high wood utilization countries such as U.S and Japan (Buchanan and Levine, 1999; Zwerger and Olgiati, 2015). In accordance with other existing studies (Khasreen et al., 2009; Chan et al., 2015), materials with high GHG emissions burden for per kg unit are found as steel, lime, wood, and glass. Having taken account of annual material use, steel, cement (non-concrete use), and concrete appear as the key contributors for embodied GHG emissions.

These findings quantitatively shed directions for reducing embodied GHG emissions in the building sector. As for the high GHG emissions burden materials such as steel and lime, reducing the energy use and using less $\mathrm{CO}_{2}$-intensive energy sources during manufacturing are presumably the most effective approaches. Improve the recycling of steel scrap also is an essential approach. In terms of the high consumed building materials such as concrete and brick, the focus should be on reducing consumption or looking for substitute materials with lower GHG burden such as hollow concrete blocks, stabilized soil blocks or fly ashes (Huberman and Pearlmutter, 2008). Durability enhanced materials (Franca et al., 2018; Martins et al., 2018) are also encouraged. Non-residential buildings would have one more potential way on seeking solutions for cement (non-concrete use). Since as a relatively high GHG burden material, cement (non-concrete use) is more consumed than in residential buildings. Furthermore, our results can also inform green building materials certification programs, which can evaluate GHG emissions burdens and promote cleaner production for building materials.

In terms of the spatial analysis, our findings indicate that the construction of buildings in Shanghai within the recent 17 years gradually moved from the suburb to 
the central urban, and then move to the eastern part. Embodied GHG emissions shows the similar trend. The spatial analysis findings point out directions for district-level building policies--Tying building material regulations in high embodied GHG burden district such as eastern PNA and central HP, for instance use less GHG burden materials or enhance building material recycling efficiency.

Decoupling analysis between building material consumption and GDP indicates a general trend from non-decoupling to relative decoupling in our research period. In the most recent year 2016, strong decoupling presented because the building material consumption declined in this year. Although it still remains to be seen whether this phenomenon indicate the beginning of decoupling period, we think this is much likely to happen based on the fact that Shanghai has begun to strictly control the land exploitation and construction activity.

One biggest limitation of this study lies on the building intensity data. Because of the data limitation, this study uses the data in 2014 to present the whole research period since 2000 to 2016 . We should note that as construction techniques and technological improvements change, building material density may vary at different times. We will need further investigation to collect specific building density in different time frame, especially when the research period covers longer span.

\section{Acknowledgement}

The research work is supported by grant from Chinese National Natural Science Foundation of China (No.71403170,71690241,71810107001). 


\section{References}

Akbarnezhad, A., Xiao J., 2017. Estimation and Minimization of Embodied Carbon of Buildings: A Review. Buildings. 7(1).

Alonso, C., Oteiza, I., Navarro, J.G., $2011 \square$ Environmental analysis of residential building facades through energy consumption, GHG emissions and costs// SB11 Helsinki World Sustainable Building Conference.

Benhelal, E., Zahedi, G., Shamsaei, E., Bahadori, A., 2013. Global strategies and potentials to curb $\mathrm{CO}_{2}$ emissions in cement industry. Journal of Cleaner Production. 51, 142-161.

Begum, R.A, Pereira, J.J., 2010. GHG emissions and energy efficiency potential in the building sector of malaysia. Australian Journal of Basic \& Applied Sciences. 4(10), 5012-5017.

Buchaan, A.H., Levine S.B. 1999. Wood based building materials and atmospheric carbon emissions. Environmental science and policy. 2(6):427-437

Chan, CK.; Leung, TM.; Ng, WY., 2015.A review on Life Cycle Assessment, Life Cycle Energy Assessment and Life Cycle Carbon Emissions Assessment on buildings. Applied Energy. 143 (1), 395-413.

Chang, Y., Huang, Z.Y, Ries, R.J., et al. 2016. The embodied air pollutant emissions and water footprints of buildings in China: a quantification using disaggregated input-output life cycle inventory model. Journal of Cleaner Production. 113(2), 274-284.

China Building Industry Press. Building Construction Manual.2003 Beijing: China Building Industry Press.

China Report Hall. 2008-2009. China Construction Market Depth Analysis and Development Trend Research Report in 2008-2009. http://www.chinabgao.com/report/43256.html (accessed on 24 June 2018)

Diakoulaki, D., Mandaraka, M., 2007. Decomposition analysis for assessing the progress in decoupling industrial growth from $\mathrm{CO} 2$ emissions in the $\mathrm{EU}$ manufacturing sector. Energy Economics. 29, 636-664.

Dimoudi, A., Tompa, C., 2008. Energy and environmental indicators related to construction of office buildings Resources. Conservation and Recycling, 53 (1-2), 86-95.

Franca, B.R., Azevedo, A.R.G., Monteiro, S.N., Filho, F.D.C.G., Marvila, M.T., Alexandre, J., Zanelato, E.B. 2018.Durability of Soil-Cement Blocks with the Incorporation of Limestone Residues from the Processing of Marble. Material research. 21.

Galvez-Martos, J.-L., Schoenberger, H., 2014. An analysis of the use of life cycle assessment for waste co-incineration in cement kilns. Resources Conservation Recycling. 86, 118-131.

Goedkoop, M., Heijungs, R., Huijbregts, M., De Schryver, A., Struijs, J., Van Zelm, R., 2009. A Life Cycle Impact Assessment Method Which Comprises Harmonized Category Indicators at the Midpoint and the Endpoint Level. First edition Report I: Characterization. http://www.lciarecipe.net.(accessed on 14 May 2018)

Hammond, G.P.; Jones, C.I., 2006. Inventory of carbon and energy. United Overseas Bank Ltd. London, UK.

Han, J., Xiang, W.N., 2013. Analysis of material stock accumulation in China's Infrastructure and its regional disparity. Sustainability Scinence. 8(4), 553-564.

Hauschild M Z, Huijbregts M A J.2015. Introducing Life Cycle Impact Assessment. Life Cycle Impact Assessment. 
He, X.S., Liu, Y., Li T.W., et al. 2013. Does the rapid development of China's urban residential buildings matter for the environment? Building and Environment. 64(64), 130-137.

Hong, L.X., Zhou, N., Feng W., et al. 2016. Building stock dynamics and its impacts on materials and energy demand in China. Energy Policy. 94, 47-55.

Hong, T., Ji, C. Y., Jang, M. H., \& Park, H. S. (2014). Assessment model for energy consumption and greenhouse gas emissions during building construction. Journal of Management in Engineering, 30(2), 226-235.

Huang, B.J., Zhao, F., Yin Y., et al. 2017. Embodied environmental impact of building materials. Research of Environmental Science. 30 (6), 929-936. (in Chinese)

Huang, C., Han, J., Chen, W.Q., 2015. Changing patterns and determinants of infrastructures' material stocks in Chinese cities. Resources, Conservation and Recycling. 123, 47-53.

Huang, T., Shi, F., Tanikawa, H., et al. 2013. Materials demand and environmental impact of buildings construction and demolition in China based on dynamic material flow analysis. Resources, Conservation and Recycling. 72(2), 91-707.

Huberman, N., Pearlmutter, D., 2008. A life-cycle energy analysis of building materials in the Negev desert. Energy and Buildings. 40,837-848.

IEA (International Energy Agency), 2009. Cement Technology Roadmap.

Intergovernmental panel on climate change, 2014. "Climate Change 2014: synthesis report", Contribution of Working Groups I, II and III to the Fifth Assessment Report of the Intergovernmental Panel on Climate Change. IPCC.

Khasreen, MM.; Banfill, PFG.; Menzies, GF. 2009. Life-Cycle Assessment and the Environmental Impact of Buildings: A Review. Sustain. 1 (3), 534-544

Kuramochi, T., 2016. Assessment of midterm CO2 emissions reduction potential in the iron and steel industry: a case of Japan.Journal of Clean Production. 132, 81-97.

Li, W., Sun, S., Li H., 2015. Decomposing the decoupling relationship between energy-related $\mathrm{CO}_{2}$ emissions and economic growth in China. 79, 977-997.

Li, Y., Beeton, R.J.S., Halog, A., et al. 2016. Evaluating urban sustainability potential based on material flow analysis of inputs and outputs: A case study in Jinchang City, China. Resources, Conservation and Recycling. 110, 87-98.

Nägeli, C., Camarasa, C., Jakob, M., et al. 2018. Synthetic building stocks as a way to assess the energy demand and greenhouse gas emissions of national building stocks. Energy and Buildings. 173, 443-460.

National Bureau of Statistics of the People's Republic of China, 2001-2017. China Statistical Yearbook. China Statistics Press, Beijing.

OECD (organlzatlon for Economlc Cooperatlon and Development). 2002. Indicators to measure decoupling of environmental pressure from econmic growth. Paris: OECD.

Rasmussen, F.N., Malmqvist T., Moncaster A., et al. 2018. Analysing methodological choices in calculations of embodied energy and GHG emissions from buildings. Energy \& Buildings. 158, 1487-1498.

Schryver A M D, Brakkee K W, Goedkoop M J, et al., 2009 Characterization factors for global warming in life cycle assessment based on damages to humans and ecosystems. Environmental Science \& Technology. 43(6):1689-95. 
Shanghai Chongming District Development and Reform Commission http://fgw.shcm.gov.cn/new_cmfgw_fzggdt_ghjh/2016-11-30/Detail_565396.htm. (accessed on 14 June 2018)

Shanghai Jinshan District Government Documents. http://jsq.sh.gov.cn/gb/shjs/zcfg/gfxwj/u1ai113054.html (accessed on 25 June 2018)

Shanghai Municipal Planning and Land Resources Administration, 2006-2020. http://www.shgtj.gov.cn/tdgl/200812/t20081223_152679.html. (accessed 24 June 2018)

Shanghai Qingpu District Economic Committee. http://econ.shqp.gov.cn/gb/content/201505/29/content 740989.htm (accessed on 14 June 2018)

Shanghai Urban Master Plan,2018. (2017-2035). http://www.shanghai.gov.cn/nw2/nw2314/nw32419/nw42806/index.html (accessed on 24 June 2018).

Sheinbaum, C., Ozawa, L., Castillo, D., 2010. Using logarithmic mean Divisia index to analyze changes in energy use and carbon dioxide emissions in Mexico's iron and steel industry. Energy Economics. 32, 1337-1344.

Sjöström, M., Östblom, G., 2010. Decoupling waste generation from economic growth--A CGE analysis of the Swedish case. Ecological Economics. 69(7), 1545-1552.

SMSB (Shanghai Municipal Statistics Bureau), 2001-2017.Shanghai Ststistical Yearbook. China Statistical Press, Shanghai.

Tanikawa, H., Hashimoto, S., 2009. Urban stock over time: spatial material stock analysis using 4dGIS.Building Research and Information. 37(5-6), 483-502.

Tapio, P., 2005. Towards a theory of decoupling: degrees of decoupling in the EU and the case of road traffic in Finland between 1970 and 2001. Transport Policy. 12(2), 137-51.

Vavrek R., Chovancova J., 2016. Decoupling of Greenhouse Gas Emissions from Economic Growth in V4 Countries 败. Procedia Economics \& Finance. 39, 526-533.

Valderrama, C., Granados, R., Cortina, J.L., Gasol, C.M., Guillem, M., Josa, A., 2012. Implementation of best available techniques in cement manufacturing: a lifecycle assessment study. Journal of Cleaner Production. 25, 60-67.

Vehmas, J., Luukkanen, J., Kaivo-oja, J., 2007. Linking analyses and environmental Kuznets curves for material flows in the European Union 1980-2000. Journal of Cleaner Production. 15, 16621673.

Wang, Y.L, Zhu, Q.H, Geng, Y. 2013. Trajectory and driving factors for GHG emissions in the Chinese cement industry. Journal of Cleaner Production. 53, 252-260.

Wang, Y., Xie, T., Yang, S. 2017. Carbon emission and its decoupling research of transportation in Jiangsu Province J. Clean. Prod. 142,907-914.

Wang, Z., Yang, L. 2015. Delinking indicators on regional industry development and carbon emissions: Beijing-Tianjin-Hebei economic band case. Ecological Indicators. 48,41-48.

Wiik, M.K., Fufa, S.M., Kristjansdottir, T., et al. 2018. Lessons learnt from embodied GHG emission calculations in zero emission buildings (ZEBs) from the Norwegian ZEB research centre. Energy and Buildings. 165, 25-34.

Yan, H., Shen, Q., Fan, L.C.H., et al. 2010. Greenhouse gas emissions in building construction: A case study of One Peking in Hong Kong. Building and Environment. 45(4), 949-955. 
Yu, B., Li X., Qiao, Y., et al. 2015. Low-carbon transition of iron and steel industry in China: carbon intensity, economic growth and policy intervention. Journal of Environmental Science. 28, 137147.

Yu, Y.D., Zhou, L., Zhou, W.J., et al. 2017. Decoupling environmental pressure from economic growth on city level: The Case Study of Chongqing in China. Ecological Indicators. 75, 27-35.

Zhao, P., Gong, X.Z., Ling, B.R., et al. 2014. Evaluation and Material Selection System for Green Building Materials. Beijing. China Building Material Industry Press.

Zhao, X., Zhang, X., Shao, S., 2016. Decoupling CO2, Emissions and Industrial Growth in China over 1993-2013: The Role of Investment. Energy Economics. 60,275-292.

Zwerger, K, Olgiati,V. 2015. Wood and wood joints: building traditions of Euroope, Japan and China. Berlin.Germany 